\title{
Ground-Penetrating Radar Applied to the Gas Station House Underground Emptied Tilt
}

\author{
Ming-Chih Lin, Yu-Ming Kang, and Kun-Fa Lee
}

\begin{abstract}
Using non-destructive Ground-Penetrating Radar(GPR) to New Taipei City Wulai Xindian river water source protection area gas station house tilted surveying the situation, reference drilling report compared the results. Ground-Penetrating Radar detection station house tilt results accurately identify the reasons. Because of that station house tilted backward about 3 5 degrees and 3/4 station house is located in a dense rock, so it does not affect the station house collapsed.
\end{abstract}

Index Terms-Ground-penetrating $\operatorname{radar}($ GPR), tilt, collapse.

\section{INTRODUCTION}

In order to understand whether the gas station house building tilt danger of collapse, thus ground-penetrating radar to detect, to understand whether there is a subterranean formation station house emptied phenomenon stratum structure and master stations. Ground penetrating radar is the use of wave reflection principle to detect the target, Fig. 1 is a schematic diagram of ground-penetrating radar surveying, $T x$ representative transmit antenna, $\mathrm{Rx}$ representing the received antenna. Transmitted wave through the formation of surface ground penetrating radar moves along the bottom of the interface when it reaches the surface, reflected waves back to the ground by the receiving antenna, the shape of the lower figure generated images and interface.

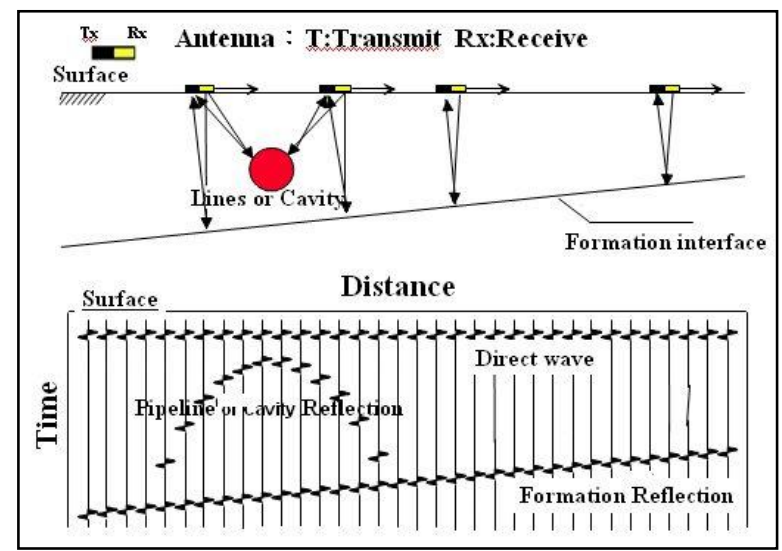

Fig. 1. GPR survey schematic diagram.

The use of Ground-Penetrating Radar geophysical survey systems, Inc. SIR-3000 host company and Hight Power $100 \mathrm{MHz}$ antenna.

Manuscript received December 20, 2013; revised February 26, 2014

Ming-Chih Lin and Yu-Ming Kang are with Feng Chia University Doctoral students Program in Civil and Hydraulic Engineering, Taiwan. (e-mail: s9051449@yahoo.com.tw, yumkang@mail.fcu.edu.tw).

Kun-Fa Lee is with Chinese Petroleum Corp. Exploration \& Development Research Institute (e-mail: h70331kf@yahoo.com.tw).

\section{LITERATURE REVIEW}

From penetrating radar in the past, has emptied many experts to detect and outcomes research, example: (2003) [1] C. Maierhofer, Concrete infrastructure assessment. (2009) [2] G. Mori, evaluate levee safety. (2010) [3] D. P. Monica, Embankment monitored. (2010) [4] T. R. Ezzy t...et, Hydrogeology and groundwater modeling coastal plains. (2012) [5] X. B. Liu, Dike emptied and plate wet testing. (2012) [6] X. T. Han, Dike emptied and reinforcement corrosion testing. (2011) [7] M. R. Wang, Wave reflection and refraction method to explore concrete seawall cracks and holes. (2010) [8] X. C. Geng, et al., Concrete dike structures emptied testing. (2009)[9]X. C. Geng...etc, Roadbed and embankments emptied testing. (2007)[10]W. T. Wu and R. G. Zhang, Road underground testing. (2003)[11]K. F. Lee...etc, Data parsing underground voids examples discussed. (2003)[12] C. K. Chang, Dykes whole detection and analysis database creation. (2000) [13] C. J. Xu, of the earth environmental investigation. (1999)[14]C. H. Yang. and L. R. Dong, Ground-penetrating radar technology. (1996) [15] Z .G. Zhou, Civil Engineering.

\section{GROUND PENETRATING RADAR SURVEYING}

Ground penetrating radar needed a total of four survey lines (Table I and Fig. 2 - Fig. 5)

\begin{tabular}{|c|c|c|c|c|}
\hline No & File No & $\begin{array}{l}\text { Line Length } \\
\text { (m) }\end{array}$ & $\begin{array}{l}\text { Line depth } \\
\text { (m) }\end{array}$ & Direction \\
\hline 1 & 265 & 21 & 15 & WE \\
\hline 2 & 268 & 8 & 15 & SN \\
\hline 3 & 266 & 4.2 & 15 & WE \\
\hline 4 & 270 & 3 & 15 & NS \\
\hline
\end{tabular}

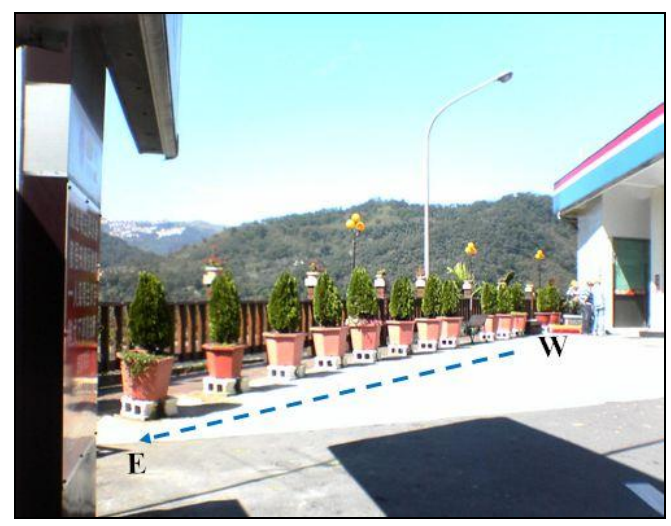

Fig. 2. Ground-penetrating radar WE survey line 265.

Then take Taiwan Kajima Engineering Consultant Co., Ltd. related to geological drilling core were compared, inspection 
of the station house at about nine meters underground formation does have emptied the following, drill core data shown in Fig. 6.

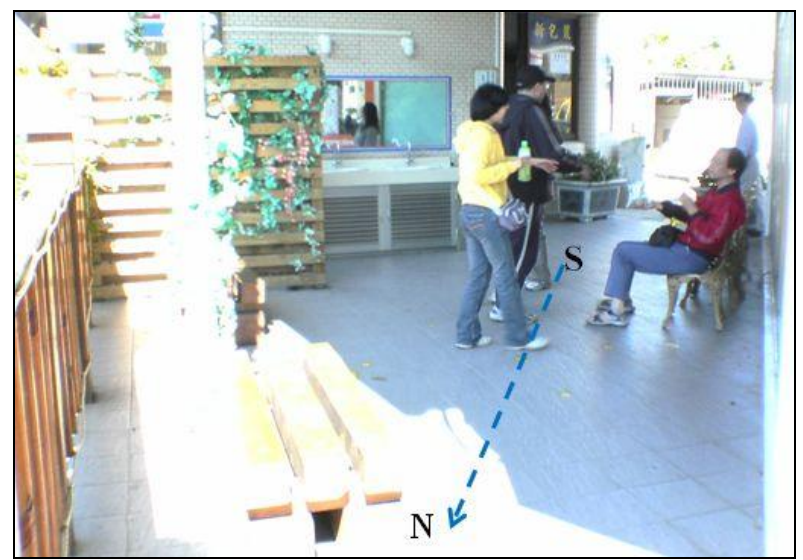

Fig. 3. Ground-penetrating radar SN survey line 268.

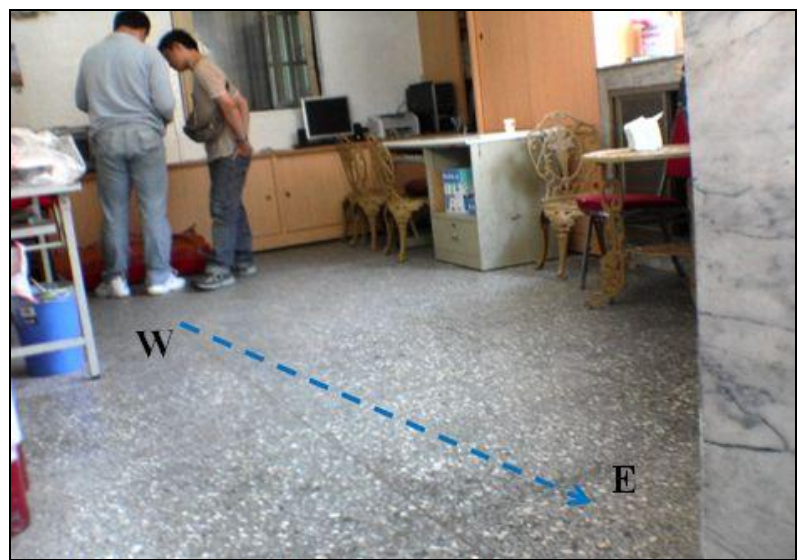

Fig. 4. Ground-penetrating radar WE survey line 266.

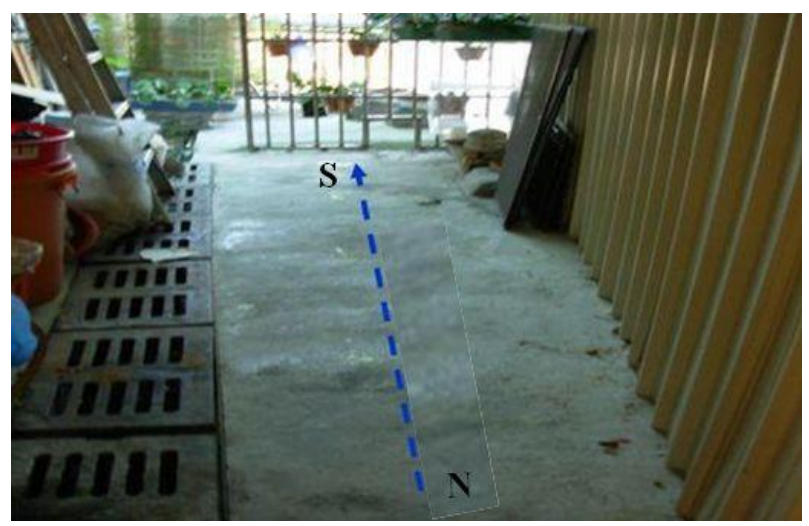

Fig. 5. Ground-penetrating radar NS survey line 270.

\section{DATA PROCESSING, ANALYSIS, INTERPRETATION}

Ground penetrating radar station house building ground stations emptied, to the depth of detection works in the data processing, and then to explain the interception optimum profile analysis, the following results can be presented in a clear profile data performance emptied location. analysis explained as follows:

Fig. 7 section emptied about $3.2 \sim 5.2 \mathrm{~m}$ and $15.5 \sim 18.5 \mathrm{~m}$ position, a depth of about 10 and $10.8 \mathrm{~m}$, hollowed out by a cross-section shows two points from a depth of about 10 $10.8 \mathrm{~m}$ after presenting a flat surface extending downward, where there are septic tanks (approximately $2.5 \mathrm{~m}$ length and width), the stage hands have crashed at about $1 \mathrm{~m}$ down situations. There is a $3 \mathrm{ft} \times 6 \mathrm{ft}$ thick steel barrier in five minutes at $15.5 \sim 18.5 \mathrm{~m}$

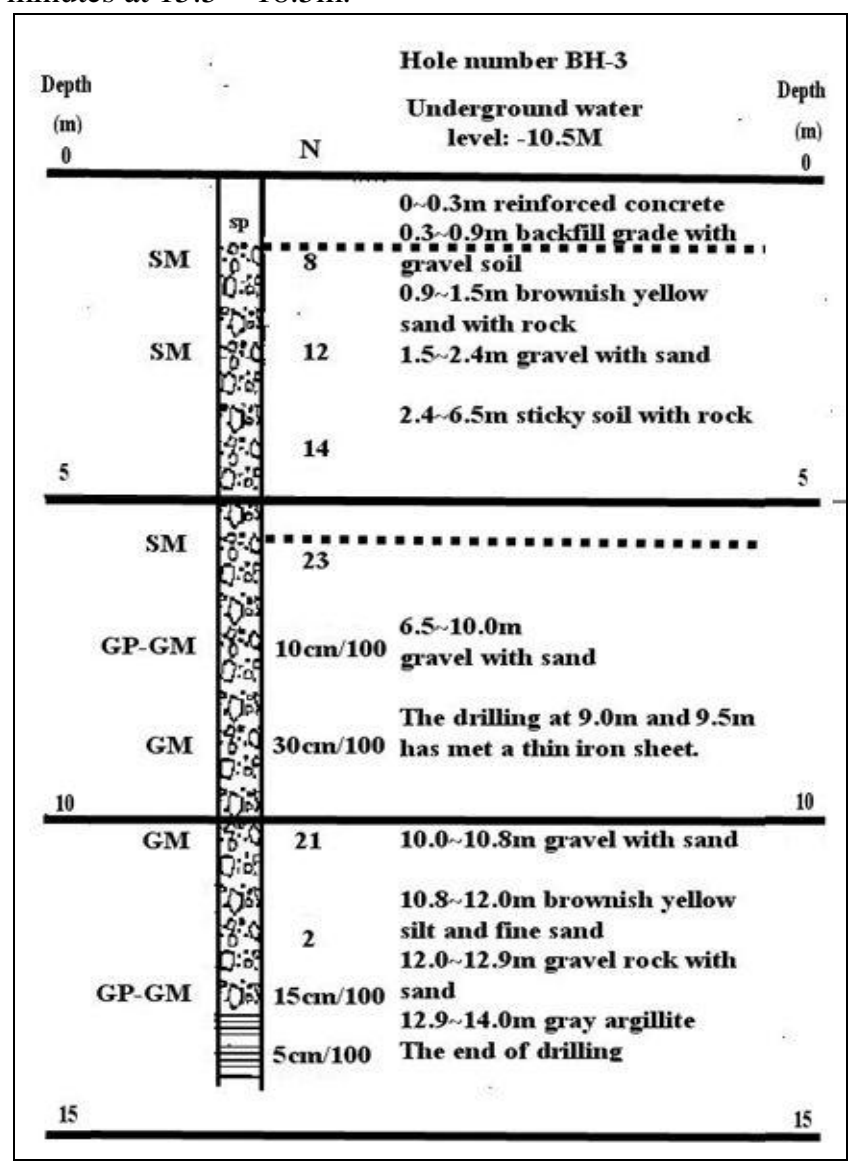

Fig. 6. Core cross-sectional data.

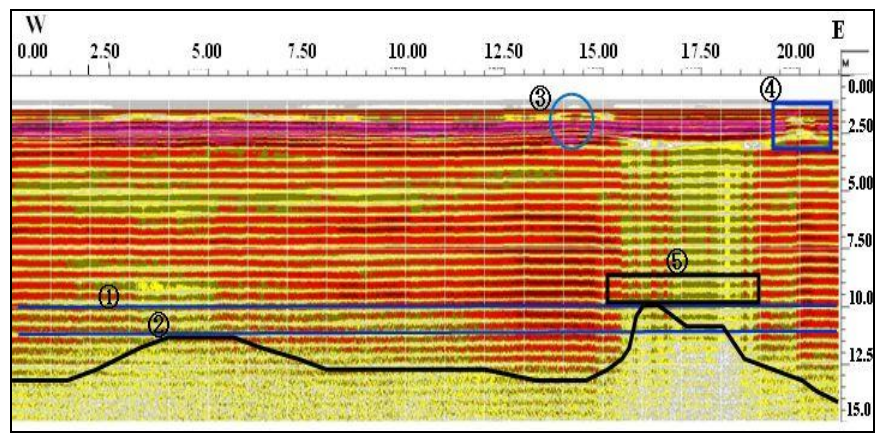

Fig. 7. Ground-penetrating radar W-E survey lines $265 \mathrm{WE}$ direction section.(1)Depth:10m (2)Depth:10.8m (3)Monitoring wells (4)Ditch (5)Steel plate $3 \times 6$ feets).

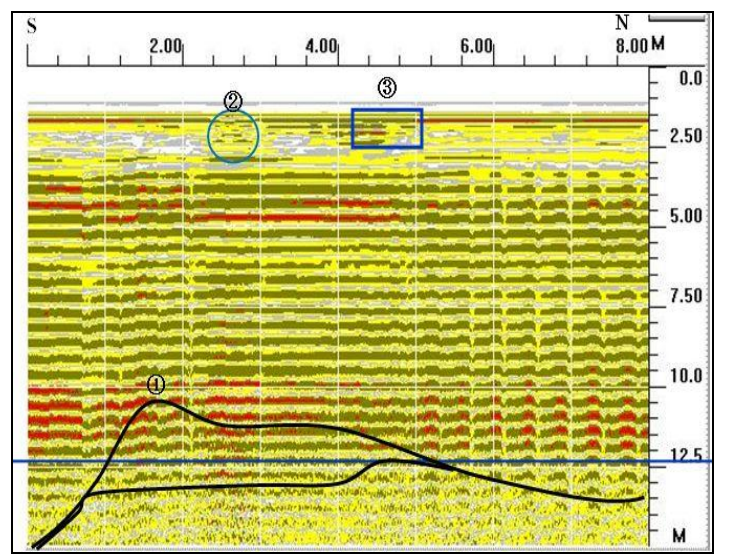

Fig. 8. Ground-penetrating radar SN survey lines $268 \mathrm{SN}$ direction section.(1)Depth:12.48m (2) Monitoring wells (3)Ditch). 
Fig. 8 section hollowed position about $3 \mathrm{~m}$ depth of $10.8 \mathrm{~m}$, as File265 file extension, the depth of File265 to 268 file extension changes seen in depth from about $10.8 \sim 10.48 \mathrm{~m}$, may be due to changes in surface topography, and almost horizontal direction then the next crashed.

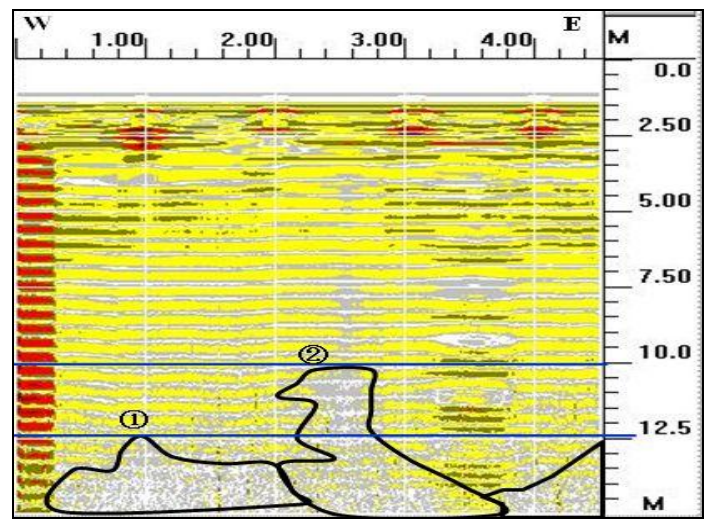

Fig. 9. Ground-penetrating radar WE survey lines 266 WE direction section.(1)Depth:12.48m (2)Depth:10.2m)

Fig. 9 section hollowed position about $1 \mathrm{~m}$, depth of $12.48 \mathrm{~m}$, as File268 extension file, the depth of the File268 to 266 file, change the extension to see the depth of about $10.2 \sim 12.48 \mathrm{~m}$, due to changes in subsurface formations emptied the worst, followed by local crashed almost directly down.

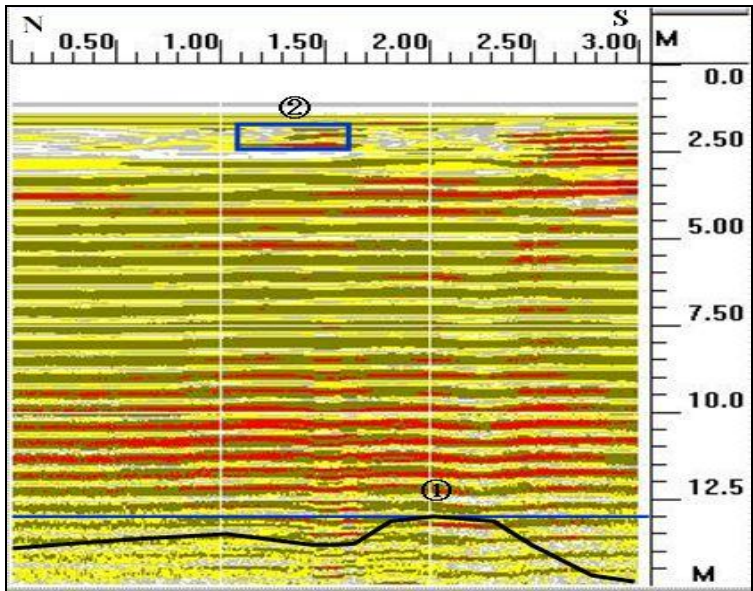

Fig. 10. Ground-penetrating radar NS survey lines 270 NS direction section.(1)Depth:13 m (2)Ditch).

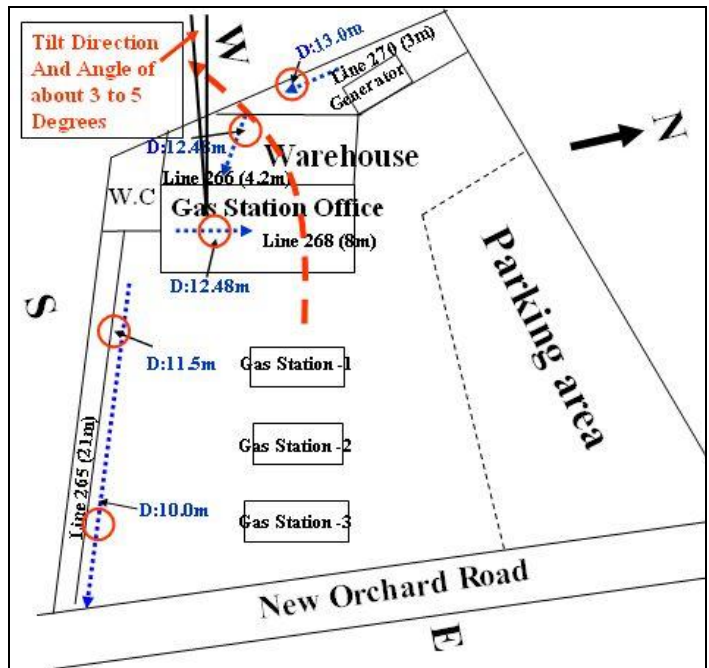

Fig. 11. Overall Gas stations and station house building range assessment tilt back schematic.
Fig. 10 section emptied location approximately $3 \mathrm{~m}$, depth of about $13.0 \mathrm{~m}$ File266 file for the extension of its depth from the File266 to 270 files, see the depth extension varies from about $12.48 \sim 13.0 \mathrm{~m}$, an underground formation cut by river water erosion caused emptied (back filling stations New Taipei City Xindian,), subsidence, and by measuring station house tilted backwards (about 3 to 5 degrees) show steady last change phenomenon.

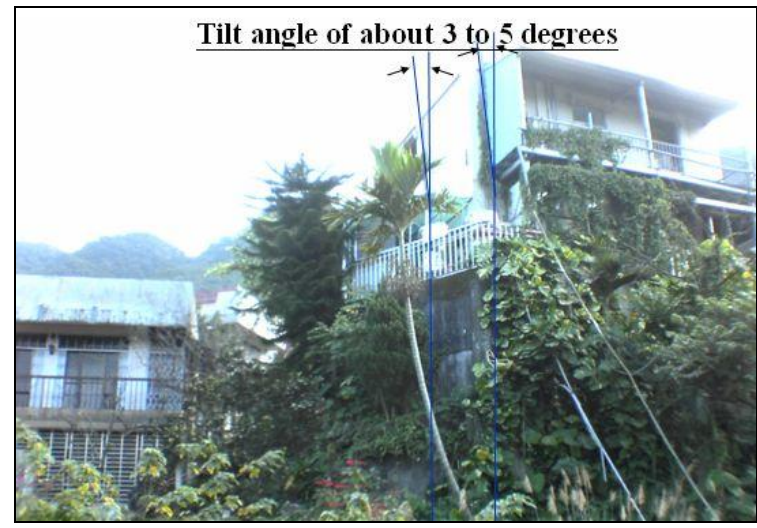

Fig. 12. Tilt the back of the gas station house building (Tilt angle of about 3 to 5 degrees).

\section{CONCLUSION}

From Ground-Penetrating Radar cross-section and core drilling report data, the gas station house is emptied and tilted backward about 3 to 5 degrees (see Fig. 11 and Fig. 12), but the whole building is located on the rugged rock formations, So there is no danger of collapse and fixed-time prosecutors.

\section{REFERENCES}

[1] C. Maierhofer, "Nondestructive Evaluation of Concrete Infrastructure with Ground Penetrating Radar," Journal of Materials in Civil Engineering, vol. 15, no. 3, pp. 287-297, 2003.

[2] G. Mori, "The use of ground penetrating radar and alternative geophysical techniques for assessing embankments and dykes safety," Modellistica fisica per la protezione dell'ambiente, 2009.

[3] D. P. Monica, "Application of gpr to the monitoring of river embankments," Journal of Applied Geophysics, vol. 71, no. 2-3, pp 53-61, June 2010

[4] T. R. Ezzy et al., "Applying ground penetrating radar to improve hydrogeological understanding and groundwater modeling within a coastal plain," Geophysical Techniques, pp. 149-156, 2010.

[5] X. B. Liu, "Through research and humid dike emptied radar used in the detection of the plate," Taiwan Chaoyang University of Technology Department of Construction Engineering Master, Master Thesis, 2012.

[6] X. T. Han, "Hollowed ground-penetrating radar used in embankments and steel corrosion detection," M.S. thesis, Institute of Soil Engineering, Chung Yuan Christian University, Taiwan Taoyuan, 2012.

[7] M. R. Wang, "The use of ground-penetrating radar reflection and refraction explore concrete seawall possible cracks and holes," M.S. thesis, National Taiwan Ocean University, Institute of Applied Geosciences, Keelung, 2011.

[8] X. C. Geng, J. G. Zheng, Y. Q. Lin, and Z. H. Jiang, "Detection of concrete dike structures hollowed out," Taiwan Concrete Institute, vol. 4, no. 4, pp. 23-35, 2010.

[9] X. C. Geng, J. G. Zheng, and Z. H. Jiang, "Roadbed and embankments emptied of detection," Taiwan the sixth seminar of Public Works, pp. 123-237, 2009.

[10] W. T. Wu and R. G. Chang, "Applied Research ground penetrating radar to detect the road," Taiwan advanced Engineering Journal, vol.2, no. 4 , pp. 225-231, 2007.

[11] K. F. Lee, S. Q. Liang, R. Z. Wu, and C. Z. Huang, "Ground-penetrating radar data used in underground cavities 
analytical detection investigate instances," in Proc. Chinese Geological Society Annual Conference, pp. 89-94, 2003.

[12] C. K. Chang, "Dykes hole detection analysis and database creation," $\mathrm{PhD}$ thesis, Department of Civil Engineering, National Cheng Kung University, 2003.

[13] C. J. Xu, "Penetrating radar survey of the applications in the earth environment," M.S. thesis, The Institute of Civil Engineering, National Cheng Kung University, 2000.

[14] C. H. Yang and L. R. Dong, "Ground-penetrating radar technology," Taiwan the first non-destructive testing technology of Public Works Symposium, pp. 125-165, 1999.

[15] Z. G. Zhou, "Ground-penetrating radar on a preliminary study of civil engineering applications," M.S. thesis, Institute of Civil Engineering, Taiwan National Cheng Kung University, 1996

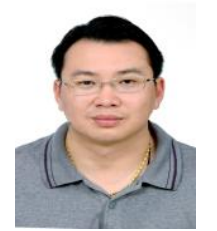

Ming-Chih Lin was born in 1975 in Fenyuan Township, Changhua County, Taiwan. In 1986, he graduated from Taiwan-South Wing Industrial College of Civil Engineering Division with five professionals. In 2004, he graduated from the Department of Construction Engineering at Chaoyang University of Technology of Taichung II Technology. In 2007, he graduated with the master degree from the Civil Engineering, Feng Chia University. His research interests are geotechnical engineering research penetrating radar, and the major oil pollution research. Currently he is in the sixth grade in geotechnical engineering Research, penetrating radar and the major oil pollution research. Currently he is serving in Changhua County, Fenyuan Township, Township Office Environment Division. In the past, he was engaged in engineering consulting firm in the design engineering planning and supervision of the work, in class-based civil engineering and landscape design. 